\title{
HUBUNGAN PERAN KADER DENGAN MOTIVASI MASYRAKAT DALAM PEMANFAATAN POSYANDU LANSIA
}

\author{
Agus Rianto \\ riantoagus585@gmail.com \\ Program Studi Ilmu Keperawatan STIKes Awal Bros Batam
}

\begin{abstract}
ABSTRAK
Latar belakang Permasalahan jumlah kunjungan lansia diposyandu sawit desa linau, masih sedikit yang hadir dalam mengikuti kegiatan posyandu, dikarenakan kurang aktipnya peran serta kader dalam menjalankan program kerja posyandu dan juga kebiasaan, kesadaran masyarakat terhadap kegiatan posyandu. Tujuan Penelitian ini bertujuan menganalisis hubungan antara peran kader dengan motivasi masyarakat dalam pemanfaatan posyandu lansia desa linau kecamatan Lingga Utara tahun 2020. Desain Penelitian. Merupakan penelitian Analitik observasional dengan menggunakan pendekatan Cross Sectioanal, Populasi dalam penelitian ini adalah seluruh lansia Desa Linau berjumlah 141 orang yang berada diwilayah kerja posyandu sawit desa Linau, sedangkan semple yang diambil sebanyak 58 orang dengan tehnik Sample Random Sampling, pengumpulan data penelitian menggunakan Kuesionert dan tehnik analisis data menggunakan uji Chi square. Hasil Penelitian. Menunjukan hasil pengaruh yang diberikan kedua variabel bebas bersipat positif artinya semakin tinggi peran kader dan motivasi masyarakat maka mengakibatkan semakin tinggi pula pemanfaatan posyandu lansia, hasi uji diperoleh $P$, volue : 0,00 $(<0,05)$ menunjukan adanya hubungan peran kader dengan motivasi masyaraat dalam pemanfaatan posyandu lansia desa linau kecamatan lingga utara. Kesimpulan Diharapkan agar kader posyandu lebih berperan aktip lagi dalam menjalakan kinerjanya sesuai dengan tugas dan poksinya sebagai seorang kader posyandu, dan masyarakat lebih peka terhadap lingkungan terutama lansia agar lansia yang ada disekitarnya menjadi lansia yang sejahtera tercapai tingkat derajat kesehatan lansia desa yang optimal.
\end{abstract}

Kata Kunci : Peran kader, motivasi masyarakat, pemanfaatan posyandu lansia

\section{THE ROLE OF CADRES WITH COMMUNITY MOTIVATION IN THE UTULIZATION OF ELDERLY POSYANDU}

\author{
Agus Rianto \\ Program Studi Ilmu Keperawatan STIKes Awal Bros Batam \\ riantoagus580@gmail.com
}

\begin{abstract}
Background The problem with the number of elderly visits at the Palm Oil Village in Linau Village, only a few people attended the posyandu activities, due to the lack of active participation of cadres in carrying out posyandu work programs and habits, public awareness of posyandu activities. The purpose of this study aims to analyze the relationship between the role of cadres and community motivation in the use of posyandu for elderly people in Linau village, Lingga Utara district in 2020. Research Design. It is an observational analytic study using the Cross Sectioanal approach. The population in this study were all elderly in Linau Village, amounting to 141 people who were in the Linau village posyandu work area, while 58 samples were taken using sample random sampling technique, research data collection using questionnaires and Data analysis techniques using the Chi square test. Research result. It shows that the results of the influence given by the two independent variables are positive, meaning that the higher the role
\end{abstract}


of cadres and community motivation, the higher the utilization of posyandu for the elderly, the results of the test are obtained $P$, volue: $0.00(<0.05)$ indicates a relationship between the role of cadres and motivation the community in the utilization of the elderly posyandu in Linau village, Lingga Utara district. Conclusion It is hoped that posyandu cadres will play a more active role in carrying out their performance in accordance with their duties and roles as a posyandu cadre, and that the community is more sensitive to the environment, especially the elderly so that the elderly around them become prosperous elderly people who achieve optimal health status of the village elderly.

Keywords: The role of cadres, community motivation, utilization of posyandu for the elderly

\section{PENDAHULUAN}

Salah satu indikator keberhasilan pembangunan adalah semakin meningkatnya usia harapan hidup penduduk menyebabkan jumlah penduduk lanjut usia terus meningkat dari tahun ke tahun. Berdasarkan data Perserikatan Bangsa- bangsa (PBB) tentang World Population Ageing, "diperkirakan pada tahun 2015 terdapat 901 juta jiwa penduduk lanjut usia di dunia. Jumlah tersebut diproyeksikan terus meningkat mencapai 2 (dua) miliar jiwa pada tahun 2050 (UN, 2015). Seperti halnya yang terjadi di negara-negara di dunia, Indonesia juga mengalami penuaan penduduk tahun 2019, jumlah lansia Indonesia diproyeksikan akan meningkat menjadi 27,5 juta atau $10,3 \%$, dan 57,0 juta jiwa atau $17,9 \%$ pada tahun 2045" (BKKBN Demografi, 2019).

Salah satu upaya pemerintah untuk meningkatkan derajat kesehatan bagi lansia adalah dengan merencanakan pembentukan posyandu khusus lansia di tingkat pedesaan. Keberadaan posyandu lansia diharapkan mampu meningkatkan mutu kehidupan lansia melalui pelayanan kesehatan dasar. Posyandu lansia merupakan kegiatan dibidang pelayanan kesehatan khusus bagi lansia di suatu wilayah tertentu berbasis masyarakat dan didukung petugas kesehatan puskesmas terdekat (Astuti, 2017).

Suatu negara dikatakan memiliki struktur penduduk tua jika mempunyai populasi lansia diatas tujuh persen, menganalogkan pada batasan tersebut, maka kepulauan Riau belum masuk dalam katagori tersebut, namun masalah lansia tidak boleh diabaikan, karena bagaimana pun juga lansia bagian dari penduduk yang memerlukan perhatian khusus seperti masalah kesehatan dan kesejahteraannya, semakin sehat dan sejahtera penduduk lansia, maka semakin maju daerah tersebut, jika kesehatan lansia semakin baik, maka harapan hidupnya semakin meningkat, "dengan demikian kesehatan dan kesejahetraan lansia menjadi salah satu indikator keberhasilan pembangunan sekaligus sebagai tantangan dalam pembangunan, menurut hasil susenas pada tahun 2018 persentase struktur penduduk lansia provinsi kepri, penduduk lansia terbagi menjadi lansia muda (60-69 tahun) sebesar 3,22 persen lansia menengah (7079 tahun) 1,09 persen dan lansia tua (80 tahun keatas) 0,26 persen, sementara itu pra lansia yaitu 45-54 tahun dan 55-59 tahun masing-masing sebesar 10,92 persen dan 2,83 persen, jumlah lansia dikepulauan Riau adalah 4,57 persen dari total seluruh penduduk dikepulauan Riau" (BPS Provensi Kepri 2018).

Berdasarkan penelitain sebelumnya yang dilakukan oleh Rusmin (2017) bahwa "faktor-faktor kendala dalam posyandu lansia antara lain pengetahuan lansia tentang manfaat posyandu, jarak rumah dengan lokasi posyandu, kurangnya dukungan dan motivasi, sikap yang kurang baik terhadap petugas posyandu atau kader. Untuk meningkatkan kesadaran 
lansia tentang pentingnya berkunjung ke posyandu lansia diperlukan kegiatan seperti : adanya penyuluhan kesehatan di desa masing-masing, pemeriksaan kesehatan secara berkala, peningkatan olahraga, pengembangan keterampilan, bimbingan pendalaman agama, pengolahan dana sehat" (Suseno, 2016).

Berdasarkan wawancara saat petugas melakukan kunjungan rumah keluhan dan alasan yang disamapaikan lansia terhadap permasalahan kunjungan pemanfaatan posyandu dari 8 orang, 3 lansia yang aktip melakukan kunjungan posyandu meraka mengatakan tidak mengetahui dan kurangnya informasi tentang jadwal posyandu sehingga tidak hadir pada kegiatan posyandu saat bulan itu, 2 lansia mengatakan malas untuk berpergian tidak ada teman keposyandu, 2 lansia lainyan mengatakan sibuk dengan pekerjaan dan 1 lansia mengatakan dia selama ini tidak tahu dengan adanya kegiatan posyandu lansia desa, dari permasalahan dan keluhan lansia diatas yang berdampak pada rendahnya jumlah kunjungan maka kinerja peran kader perlu diperhatikan dan lansia yang malas melakukan kunjungan butuh dukungan suport agar semangat motivasi dari luar, motivasi dari masyarakat tentang pemanfaatan posyandu terarahkan. untuk itu peran kader dan motivasi perlu dikaji untuk mengetahui adakah hubungan peran kader dengan motivasi masyarakat terhadap pemafaatan posyandu desa Linau Kecamatan Lingga Utara.

Berdasarkan permasalahn di atas, peneliti tertarik untuk melakukan penelitian tentang "Hubungan Peran Kader dengan Motivasi Masyarakat dalam Pemanfaatan Posyandu Lansia di Desa Linau Kecamatan Lingga Utara Tahun 2020”.

\section{METODELOGI PENELITIAN}

Penelitian ini termasuk jenis penelitian "analitik observasional yaitu peneliti berupaya mencari hubungan antara variabel dan menganalisa atau menguji hipotesis yang dirumuskan Penelitian ini menggunakan pendekatan cross sectional, yaitu melakukan pengukuran variabel dependent dan independent hanya satu kali tanpa melakukan follow up. Populasi dalam penelitian ini adalah lansia di Desa Linau yang berada di wilayah kerja Puskesmas Pancur Lingga Utara, yang berjumlah 141 orang. Sampel pada penelitian ini sebanyak 58 responden".

\section{HASIL PENELITIAN}

Berdasarkan penelitian didpatkan hasil sebagai berikut :

1. Analisa Univariat

Tabel 1.1

Distribusi Frekuensi Responden Berdasarkan Jenis Kelamin

\begin{tabular}{lll}
\hline Jenis Kelamin & N & \% \\
\hline Laki-laki & 31 & $53,4 \%$ \\
Perempuan & 27 & $46,6 \%$ \\
\hline Total & $\mathbf{5 8}$ & $\mathbf{1 0 0 \%}$ \\
\hline
\end{tabular}

Berdasarkan Tabel 1.1 didapatkan hasil responden dalam penelitian ini didominasi oleh responden lakilaki sejumlah $31 \quad(52,5 \%)$ responden dan untuk responden perempuan sebanyak 27 (48,5\%) responden.

Tabel 1.2

Distribusi Frekuensi Responden Berdasarkan Usia

\begin{tabular}{lll}
\hline Usia & $\mathbf{N}$ & $\mathbf{\%}$ \\
\hline 50-59 Tahun & 23 & $39,7 \%$ \\
60-69 Tahun & 33 & $56,9 \%$ \\
70-79 Tahun & 2 & $3,4 \%$ \\
\hline Total & $\mathbf{5 8}$ & $\mathbf{1 0 0 \%}$ \\
\hline
\end{tabular}

Berdasarkan Tabel 1.2 didapatkan hasil Usia responden dalam penelitian ini didominasi oleh usia 60-69 tahun dengan jumlah 33 
(56,9\%) responden. Untuk responden usia 50-59 tahun dengan jumlah $23(39,7 \%)$ responden, dan untuk responden usia 70-79 tahun sebanyak $2(3,4 \%)$ responden.

\section{Tabel 1.3}

Distribusi Frekuensi Responden Berdasarkan Tingkat Pendidikan

Berdasarkan Tabel 1.3 Tingkat pendidikan responden dalam penelitian ini didominasi oleh tingkat pendidikan SD dengan jumlah $52(89,7 \%)$ responden, untuk tingkat pendidikan SLTP dengan jumlah $5(8,6 \%)$ responden, untuk tingkat pendidikan SLTA dengan jumlah $1(1,7 \%)$ responden.

Tabel 1.4

Distribusi Frekuensi Responden Berdasarkan Tingkat Pekerjaan

\begin{tabular}{ll}
\hline Pekerjaan & N $\%$ \\
\hline
\end{tabular}

\begin{tabular}{lll}
\hline Nelayan & 6 & $10,3 \%$ \\
Petani & 28 & $48,3 \%$ \\
Buruh Hutan & 11 & $19 \%$ \\
Swasta & 4 & $6,9 \%$ \\
Ibu rumah tangga & 9 & 15,5 \\
\hline Total & $\mathbf{5 8}$ & $\mathbf{1 0 0 \%}$ \\
\hline
\end{tabular}

\begin{tabular}{lll}
\hline Pendidikan & $\mathbf{N}$ & $\mathbf{\%}$ \\
\hline SD & 52 & $89,7 \%$ \\
SLTP & 5 & $8,6 \%$ \\
SLTA & 1 & $1,7 \%$ \\
\hline Total & $\mathbf{5 8}$ & $\mathbf{1 0 0 \%}$ \\
\hline
\end{tabular}

Berdasarkan tabel 1.4 didapatkan hasil berdasarkan pekerjaan didominasi oleh Petani yaitu sejumlah 28 reponden, dan untuk nelayan sejumlah 6 responden, untuk responden buruh hutan sejumlah 11 responden, untuk responden swasta sejumlah 4 responden dan untuk responden ibu rumah tangga sejumlah 9 responden.

2. Analisa Bivariat

Tabel 1.5

Hubungan Peran Kader Dengan Motivasi Masyarakat Dalam Pemanfaatan Posyandu Lansia Desa Linau Kecamatan Lingga Utara

\begin{tabular}{|c|c|c|c|c|c|c|c|c|}
\hline \multicolumn{9}{|c|}{ Motivasi Masyarakat } \\
\hline & & \multicolumn{2}{|c|}{ Baik } & \multicolumn{2}{|c|}{ Kurang } & \multicolumn{2}{|c|}{ Jumlah } & \multirow{5}{*}{$\begin{array}{l}p \text { - } \\
\text { Value } \\
0, \\
000\end{array}$} \\
\hline & & $\mathrm{N}$ & $\%$ & $\mathrm{~N}$ & $\%$ & $\mathrm{~N}$ & $\%$ & \\
\hline Peran & Baik & 18 & 31,03 & 1 & 1,72 & 19 & 32,75 & \\
\hline kader & Kurang & 1 & 1,72 & 38 & 31,03 & 39 & 67,24 & \\
\hline Total & & 19 & 32,75 & 39 & 32,75 & 58 & 100 & \\
\hline
\end{tabular}

Berdasarkan tabel 1.5 diatas dapat dilihat bahwa, dari 58 responden yang memiliki motivasi baik dengan peran kader baik $(31,03 \%)$. Hasil uji statistik diperoleh $P$ Value $=0,000(<0,05)$ menunjukan adanya hubungan peran kader dengan motivasi masyarakat dalam pemanfaatan posyandu lansia desa linau kecamatan lingga utara. 


\section{PEMBAHASAN}

Berdasarkan hasil pengujian secara statistika dapat dilihat dengan jelas bahwa "secara parsial (individu) semua variabel bebas berpengaruh terhadap variabel terikat. Pengaruh yang diberikan kedua variabel bebas bersifat positf artinya semakin tinggi variabel peran kader dan motivasi masyarakat maka mengakibatan semakin tinggi pula pemanfaatan posyandu lansia. Hasil uji statistik diperoleh P- Value $=0,000 \quad(<0,05)$ menunjukan adanya hubungan peran kader dengan motivasi masyarakat dalam pemanfaatan posyandu lansia desa linau kecamatan lingga utara. Temuan penelitan membuktikan bahwa variabel motivasi masyarakat berpengaruh positif dan signifikan terhadap pemanfaatan posyandu, semakin tinggi variabel motivasi masyarakat maka semakin tinggi nilai variabel pemanfaatan posyandu. Berdasarkan hasil observasi”.

3. Peran kader dan motivasi masyarakat berpengaruh terhadap pemanfaatan posyandu Desa Linau Kecamatan Lingga utara

Hasil penelitian ini membuktikan bahwa variabel peran kader dan motivasi masyarakat secara bersamasama berengaruh positif dan signifikan terhadap pemanfaatan posyandu. Semakin tinggi variabel peran kader dan motivasi masyarakat, maka semkin tinggi nilai variabel pemanfaatan posyandu. Hasil observasi ini membuktikan bahwa terdapat hubungan

\section{PENUTUP}

\section{KESIMPULAN}

1. Terdapat hubungan yang signifikan antara peran kader dalam pemanfaatan
Berikut ini merupakan penjelasan dari masing-masing pengaruh variabel sebagai berikut" :

1. Peran kader berpengaruh terhadap pemanfaatan posyandu Desa Linau Kecamatan Lingga Utara

"Temuan penelitian membuktikan bahwa variabel Peran Kader berpengaruh positif dan signifikan terhadap pemanfaatan posyandu. Maka semakin tinggi nilai variabel peran kader, maka semakin tinggi nilai varabel pemanfaatan posyandu. Berdasarkan observasi ketersedian

2. Motivasi masyarakat berpengaruh terhadap pemanfaatan posyandu desa linau kecamatan lingga utara

posyandu lansia desa linau kecamatan lingga utara.

2. Terdapat hubungan yang signifikan antara motivasi masyarakat dalam pemanfaatan posyandu lansia desa linau kecamatan lingga utara.

3. Terdapat hubungan antara peran kader dan motivasi masyarakat dalam pemanfaatan posyandu lansia desa linau kecamatan lingga utara

\section{SARAN}

1. Bagi Puskesmas "pemegaang program posyandu hendaknya melakukan upaya lebih untuk meningkatkan penyuluhan berbagai macam hal berkaitan dengan masalah kesehatan dalam pelayanan posyandu lansia sehingga dapat lebih mengerti pada masalah kesehatan serta untuk lebih memanfaatkan posyandu lansia".

2. Bagi Kader posyandu "hendaknya senantiasa meningkatkan pengetahuan dan sikap dalam memberikan pelayanan di posyandu lansia, sehingga peran kader lansia di masyarakat dapat optimal".

3. Bagi masyarakat "hendaknya untuk 
selalu memberikan perhatian dan motivasi terhadap lansia untuk mau memanfaatkan posyandu lansia".

4. Bagi seluruh lansia desa "diharapkan bisa mengikuti kegiatan posyandu lansia agar mendapatkan manfaat dari kegiatan yang diselenggarakan posyandu lansia".

\section{DAFTAR PUSTAKA}

Darwis, K. (2014). Faktor-Faktor Yang Berhubungan Dengan Kunjungan Lansia Ke Posyandu Lansia Di Wilayah Kerja Puskesmas Rapak Mahang Kabupaten Kutai Kertanegara.

Depkes, R. (2006). Pedoman pelatihan kader kelompok usia lanjut bagi Keluarga.

Direktorat Kesehatan, Jakarta.

Depkes, R. (2013). Riset kesehatan dasar. Kemenkes Republik Indonesia, Jakarta.

Dermawan, I. (2018). Faktor-Faktor yang Berpengaruh terhadap Pemanfaatan Pelayanan Posyandu Lansia di Wilayah Kerja Puskesmas Glugur Darat Medan Tahun 2017.

Iswarawanti, D. (2010). Kader posyandu: Peranan dan tantangan pemberdayaannya dalam usaha peningkatan gizi anak di indonesia. (J. Manaj, Ed.) (4th ed.). Jakarta.

Koesmono, H. . (2005). Pengaruh Budaya Organisasi terhadap Motivasi dan Kepuasan Kerja Serta Kinerja Karyawan pada Sub Sektor Industri Pengolahan Kayu Skala Menengah di Jawa Timur.
Jurnal Manajemen \&

Kewirausahaan., Vol.7.

No.(September 2005.), 17.

Mufida., K. N. K. M. (2018). FAKTOR YANG MEMPENGARUHI PERAN KADER DALAM UPAYA PERBAIKAN GIZI PADA BALITA DI WILAYAH KERJA PUSKESMAS MILA.

Nasrul, E. (1998). Dasar-Dasar Perawatan Kesehatan Masyarakat,. Jakarta. Notoatmodjo. (2012). Metodelogi Penelitian Kesehatan. Jakarta: Rineka Cipta. Nurzia, N. (2017). HUBUNGAN MOTIVASI DAN DUKUNGAN KELUARGA

$\begin{array}{lr}\text { LANSIA } & \text { DALAM } \\ \text { MELAKUKAN } & \text { KUNJUNGAN } \\ \text { POSYANDU } & \text { LANSIA DI } \\ \text { WILAYAH } & \text { KERJA } \\ \text { PUSKESMAS } & \text { SIMPANG } \\ \text { KAWAT KOTA JAMBI TAHUN } \\ 2017,6(02), 162-169 .\end{array}$

Sartika K. (2015). HUBUNGAN PERSEPSI DAN PARTISIPASI LANSIA DENGAN TINGKAT PEMANFAATAN POSYANDU.

Sulistyaningsih. (2016). Hubungan motivasi dengan frekuensi kunjungan ke posyandu laraslestari ii pada lansia di dusun karang tengah sleman yogyakarta.

Wahono, H. (2010). ANALISIS FAKTOR-FAKTOR YANG MEMPENGARUHI.

Rusmin. Paktor-Paktor Yang Berhubungan Dengan Pemanfaatan Posyandu Lansia Diwilayah Kerja Puskesmas Sombo Apu Kabupaten Gowa : 2015

Astuti T. Hubungan Dukungan Keluarga Dengan Keaktifan Lansia Mengikuti Posyandu Lansia Diposyandu Melati Klawisa Seyegan Yogyakarta : 2017 
Maria dkk. Hubungan Dukungan Keluarga Dengan Motivasi Lansia Dalam Mengikuti Kegiatan Posyandu Lansia Dikecamatan Lowokwaru Malang : 2017

Sumarmi. Peran Kader Posyandu Sebagai Agen Pembaru Bagi Lansia Dikukuh RejoSari Kecamatan Gunung Sari Semarang : 2015

Mengko, Viena Viktoria, ddk. Pemanfaatan Posyandu Lansia Diwilayah Kerja Puskesmas Teling Atas. Universitas Sam Ratulangi. Manado : 2017

Pitayani Asrina. Sikap Lansia Dan Pelayanan Petugas Kesehatan Terhadap Kunjungan Diposyandu Wilayah Puskesmas Patihan. Surabaya : 2017

Putra Deri. Faktor Yang Berhubungan Dengan Pemanfaatan Posyandu Lansia Diwilayah Kerja Puskesmas Sikapak Kota Pariaman : Padang 2015

Febri Aini. Analisis Pemanfaatan Posyandu Lansia Diwilayah Kerja Puskesmas Amplas : 2018

Profil Puskesmas Pancur Kecamatan Lingga Utara 2019

Proyeksi Bps Kabupaten Lingga : 2019

Bkkbn Pusat, Demografi : 2019

Bps Provensi Kepri : 2018

Widodo. Metode LogiPenelitian Populer Dan Praktis. Jakarta Penerbit Rajawali : 2017

Yusuf Muri. Metode Penelitian Kuantitatif, Kualitatif, Dan Penelitian Gabungan. Padang. Penerbit Kencana :2014 